\title{
Fantasmas da Escrita: Amor de perdição e o Cinema Epistolar de Manoel de Oliveira
}

\author{
CLARA ROWLAND \\ Universidade Nova de Lisboa
}

\begin{abstract}
In the closing sequence of Manoel de Oliveira's Amor de perdição (1978), Teresa's last letter to Simão Botelho reveals the phantasmagoric nature of the cinematographic image: in the posthumous temporality of its reading, Teresa enters the scene as an apparition, projected by writing and permitting the reunion, at last, of the lovers' bodies-separated throughout the film-in the same shot. Through a detailed reading of the depiction of letters in Oliveira's adaptation of Camilo Castelo Branco's novel, and of its connections to other works by the Portuguese filmmaker, this paper explores the interplay between writing, image, and authorship in what has been termed Oliveira's "epistolary cinema" and its relevance for a redefinition of the role of writing within his ideas regarding film.
\end{abstract}

Keywords: Epistolarity; writing in film; temporality; authorship; adaptation

"Dead letters! does it not sound like dead men?"

(Melville 46)

Numa entrevista com João Bénard da Costa, Manoel de Oliveira recorda que o impulso para a adaptação de Amor de perdição, de Camilo Castelo Branco, veio de José Régio, que insistia: "sobretudo leia as cartas, leia as cartas" (Bénard da Costa 106). É à correspondência entre Teresa e Simão que o livro é efetivamente assimilado, na sequência final do filme, em que uma voz em off lê, enquanto vemos um barco a resgatar das águas um rolo de papéis, palavras 
do prefácio à segunda edição de Amor de perdição. Mas não apenas o livro: a voz é a de Oliveira, e aparece aqui pela primeira vez; e também de Oliveira é a mão que segura os papéis. Se o Amor de perdição pode ser visto como um romance sobre cartas, e não apenas de cartas, também o filme se assume como tal. Pois é sobretudo em torno das cartas que se faz Amor de perdição de Oliveira: não apenas pela atenção dada, em termos narrativos, a todos os elementos epistolares do texto de Camilo, mas sobretudo pelo modo como é através da figura da carta que a reflexão de Amor de perdição em torno da sua condição de filme sobre a escrita é conduzida.

Não discutirei aqui em detalhe o problema da adaptação, ou a complexidade das soluções em causa no filme de Oliveira, alimentado, como já se sublinhou muitas vezes, ao mesmo tempo por uma recusa das correspondências entre escrita e cinema e pela sua exploração sistemática e radical. Numa famosa recensão intitulada "The Masterpiece You Missed," em que sugeria que Amor de perdição era o filme que Truffaut - o Truffaut de Les deux anglaises et le continent e La chambre verte-teria tentado fazer a vida inteira, Jonathan Rosenbaum definia-o como "a veritable workshop of ideas about the incestuous relationship between novels and movies, and the diverse possibilities of literary adaptations" (214). Sem perder de vista esta descrição, gostaria de concentrar a atenção sobre a carta, e sobre uma ideia de cinema que a carta, enquanto figura da escrita e da literatura, parece definir em Amor de perdição.

\section{Assinaturas}

Na sequência inicial de O velho do Restelo (2014), uma edição d'Os Lusíadas aflora à superfície agitada das águas do mar. A câmara filma longamente o livro a flutuar, batido pelas ondas, ora aberto, ora fechado. É a primeira indicação de que estamos, com $O$ velho do Restelo, perante uma síntese da relação do cinema de Oliveira com alguns autores a que insistentemente regressa, ou perante uma revisitação da apropriação, pelo seu cinema, de certas assinaturas (Camilo, Camões, Pascoaes) com que continuamente se confronta. Porque toda a sequência inicial—retomada, brevemente, perto do final do filme-devolve o espectador à conclusão de Amor de perdição, e à imagem duplamente assinada 
(mão e voz) da correspondência de Teresa e Simão a emergir das águas para ser resgatada num paralítico final.

João Ribeirete sugere que, neste plano inaugural de um "filme-súmula" em que Oliveira, a partir do fim, ajusta "contas com os seus," se materializa "a ideia de que o texto escrito sofre uma transformação profunda quando passa para o celuloide e é assimilado (engolido, utilizando uma metáfora menos plástica) pelo cinema" (Ribeirete 81). É uma sugestão com implicações importantes para a leitura do final de Amor de perdição, momento explícito, como veremos, de confronto de assinaturas, autorias e ideias de obra. Mas, tal como acontecerá com a citação de Camões que dá título a "Non" ou a vã glória de mandar (é o argumento do ensaio de Ribeirete), também a cena do filme de 1978 é recontextualizada pela revisitação—de impulso filológico, digamos—de O velho do Restelo. ${ }^{1}$ Porque a retomada de Amor de perdição faz-se, aqui, através da reactualização da citação, desta vez cinematográfica, que lhe está na origem: a sequência final do Amor de perdição de António Lopes Ribeiro, que Oliveira cita e desloca na sua adaptação. No final de Amor de perdição, de Camilo, recorde-se, é possível encontrar uma referência reflexiva à materialidade do próprio romance com a frase quase final que descreve o resgate da correspondência sobre a qual o romance teria sido escrito. Diz o texto de Camilo: "O comandante olhou para o sítio donde Mariana se atirara, e viu, enleado no cordame, o avental, e à flor d'água um rolo de papéis, que os marujos recolheram na lancha. Eram, como sabem, a correspondência de Teresa e Simão" (224).

Ora, se no filme de Oliveira, como vimos, é o rolo de cartas a ser recolhido pela mão do cineasta, no filme de Lopes Ribeiro, é um livro (o Amor de

\footnotetext{
1 "Com efeito, ao colocar as mesmas palavras na boca do mesmo actor (com vinte anos de permeio), provocando uma mesma associação de ideias (batalha de Alcácer Quibir-discurso do velho do Restelo), Oliveira está também a citar a segunda parte do título do seu filme anterior (vã glória de mandar), onde este verso surge, mas ligeiramente distorcido. Deste modo, o efeito não é apenas de citação/colagem das palavras camonianas proferidas ipsis verbis, mas também de eco ou de rima com o título do filme anterior, que tinha assumido o texto-fonte lato sensu. A apropriação efetuada pelo Alferes Cabrita, que cita o discurso do velho do Restelo e abandona-o no primeiro verso sem mais, não é senão o reflexo de um movimento de reescrita do texto camoniano (talvez de todo o texto literário) levado a cabo pelo realizador/autor Oliveira: "Ó glória de mandar, ó vã cobiça," de Luís de Camões, transforma-se em vã glória de mandar, de Manoel de Oliveira" (Ribeirete 83).
} 
perdição) o que aflora depois de vermos o corpo de Simão a afundar, abraçado por Mariana. Sobre as duas soluções para o final, escreve Hajnal Kiraly:

De forma semelhante, ambos os filmes mostram, na última cena, as cartas de amor que sobem até à superfície do mar depois de os corpos de Simão e Mariana terem desaparecido. Novamente, e pela última vez, a carta surge como um substituto material, um 'terceiro objeto' no lugar do corpo ausente e, ao ser encontrada, torna-se uma figura romântica da continuidade histórica, da herança e da memória. Curiosamente, enquanto na adaptação de Ribeiro as cartas flutuam na água na forma de um livro, na de Oliveira aparecem espalhadas na superfície da água. Esta última imagem ilustra de forma eloquente as diferentes abordagens dos dois autores relativamente à questão do 'original.' Para Ribeiro, este é o Livro, o tesouro encontrado, a Obra de um Autor que é único e que não pode ser substituído nem modificado. Para Oliveira, pelo contrário, não há nada mais do que um texto fragmentado, que pode ser infinitamente recriado, lido e interpretado. (Kiraly, "Cartas no ecrã" 180)

É clara a referência ao livro enquanto obra matriz no filme de Lopes Ribeiro. Em $O$ velho do Restelo, então, Oliveira parece corrigir a posteriori uma citação desviada, reativando, de Lopes Ribeiro, a figura metaforizada do livro, agora numa relação complexa-e particularmente interessante como gesto reflexivo de releitura dessa tensão ao longo da obra do próprio Oliveira-entre materialidade do livro e corporalidade encenada do autor. Parece-me, no entanto, que a relação entre cartas e livro, ou a caracterização metonímica da correspondência entre Teresa e Simão com o Amor de perdição, implícita na novela, não deixa de estar presente, de forma talvez mais radical, no filme de 1978. Porque na conclusão de Amor de perdição não podemos desvincular o que vemos na imagem (a mão que recolhe o rolo de papéis) do texto em off que acompanha a cena, até pela associação som/imagem que a dupla assinatura (sonora e visual) de Oliveira parece construir; do mesmo modo, não podemos ignorar a presença escrita, na imagem, da longa citação de Camilo que corresponde às palavras ditas por Oliveira. A sugestão de uma identificação entre as cartas em rolo e o romance Amor de perdição-referido aqui, pela 
primeira vez em todo o filme, enquanto romance e livro material—é feita através de um complexo jogo de assinaturas, ausente no filme de Lopes Ribeiro, e da associação disjuntiva entre som e imagem. ${ }^{2}$ Nesta cena, Oliveira assimila a correspondência e romance de Camilo no mesmo gesto com que a mão do cineasta, salvando da destruição os papéis, resgata o filme que acabámos de ver, e assim aproximando os papéis que são tema e material do romance de outros papéis que fazem o filme: o seu argumento. As cartas são então, ao mesmo tempo, livro e argumento, figura do texto literário que se adapta e da forma do filme que dela se alimenta, nos dois casos articulando a reflexividade da figura (um filme que se figura enquanto carta, ou um filme que identifica o momento em que o romance se representa como carta, representando-se também).

António Preto sugere que em Amor de perdição, Oliveira encontra "o protótipo de um 'cinema epistolar,' onde a história dos dois amantes se funde com a correspondência que mantiveram e com o trajeto histórico das cartas" (108). É nesta cena, último momento de um discurso sobre a carta que o filme elaboradamente constrói, que essa hipótese ganha corpo. Para o percebermos melhor, importa acompanhar de perto a sequência. No momento em que o bote se dirige ao ponto em que os corpos se afundaram, para tentar resgatar Mariana das águas, o texto que será dito por Oliveira invade o ecrã. Invade-o, porém, na condição explícita (e dupla) de citação: trata-se do excerto das Memórias do cárcere que Camilo reproduz no prefácio da segunda edição do romance; e é como texto truncado, com cortes assinalados, que é exibido. Os cortes estão apenas no plano do visível, pois enquanto lemos o texto que corre no ecrã, a voz de Oliveira lê sem pausas as palavras de Camilo:

Desde menino, ouvia eu contar a história do meu tio paterno Simão António Botelho. Minha tia, irmã dele, solicitada por minha curiosidade, estava sempre pronta a repetir o facto aligado à sua mocidade. . . . Sabia eu que em casa de minha irmã estavam acantoados uns maços de papéis antigos, tendentes a esclarecer a nebulosa história de meu tio. Pedi aos contemporâneos que o conheceram notícias e

\footnotetext{
${ }^{2}$ Recorde-se que é da reunião de todos os papéis para serem atirados ao mar com o corpo do condenado que falam Mariana e Simão perto da morte. É por isso importante que se trate de um rolo, e não de papéis dispersos.
} 
miudezas, a fim de entrar de consciência naquele trabalho. Escrevi o romance em quinze dias, os mais atormentados de minha vida. Tão horrorizada tenho deles a memória, que nunca mais abrirei o Amor de perdição. . . . Camilo Castelo Branco, Memórias do cárcere

A duplicação é evidente-e mais evidente num filme em que foram já ensaiadas todas as estratégias possíveis de representação da disjunção entre escrita, voz, imagem - e significativa: se muito se acentuou a "fidelidade" do filme de Oliveira ao texto de Camilo, é preciso ter em conta o modo como este momento final exemplifica a presença enganadora de um suposto texto "inteiro": feito de gestos de citação, montagem, corte e reordenação, o texto do filme de Oliveira é um duplo inquietadoramente parecido com uma prosa —a de Camilo - que transforma interna e incessantemente. Aqui, o texto de Oliveira apenas duplica o texto de Camilo na medida em que o desloca, ironicamente: em direção ao cinema (a voz do cineasta), a outra assinatura (a mão que segura as cartas), em direção a uma forma outra (citação, corte, montagem). Pois sobre o nome escrito de Camilo, que termina a citação, ouvimos Oliveira; e sobre o nome dito da obra - "nunca mais abrirei o Amor de perdição"-lemos o nome de outra obra, Memórias do cárcere, que rima visualmente com o filme que acabámos de ver (obsessivamente enquadrado pelas grades das prisões, iniciado por um portão a fechar-se).

"Nunca mais abrirei o Amor de perdição": a referência ao romance enquanto romance, num filme que recupera de Amor de perdição a obsessão por documentos, cartas, escritos, sem nunca explicitar, até aqui, o problema do livro, faz-se no momento em que é mais clara a inscrição de uma assinatura que, mais do que subscrever Camilo, se sobrepõe à figura do romancista, despedindo-a. Porque o texto das Memórias do cárcere, que Camilo reevoca na abertura da segunda edição, ao mesmo tempo negando o romance e relançandoo aos leitores, é lido por Oliveira no momento em que o filme se fecha: deslocado para o final, o seu valor de closure é acentuado pelo paralítico (a mão fechada num gesto claro de apropriação, a imagem que congela para o fim do filme), e também pela cesura da citação truncada, que indica que há uma forma - o filme - que se escolheu delimitar com essa frase terminal, que funciona, em certa medida, contra o livro, ao mesmo tempo negado e relançado pela identificação com o filme. Numa entrevista famosa, Oliveira afirma que 
"não é Camilo que fala, não foi ele que fez o filme," e que a sua posição, tomando, "portanto," "o seu lugar" é a de dizer "eis o que Camilo escreveu" (Parsi e de Baecque 90). A identificação entre o filme de Oliveira e a correspondência entre Teresa e Simão é, assim, a carta roubada de Amor de perdição.

\section{Cinema epistolar}

Anunciada pela voz do narrador/delator a propósito da "maravilhosa mudança nos costumes de Simão", Teresa aparece pela primeira vez identificada aos 23 minutos de Amor de perdição num plano frontal, olhando para a câmara, enquanto em off a sua voz profere um monólogo, na primeira pessoa, que a apresenta. Desse plano, passamos para um enquadramento simétrico de Simão de Albuquerque, que, sempre olhando para a câmara, profere em off o monólogo correspondente. Nos dois casos, os dois corpos estão imóveis, sendo o seu olhar fixo, como se olhassem para o espectador, a característica que os distingue. A dada altura, porém, Simão recua bruscamente, e a câmara passa a enquadrá-lo por trás, revelando, ao mesmo tempo, que os dois estão à janela, contemplando-se mudos de casa para casa, e que o pai de Teresa, entrando no quarto da filha, a surpreendeu nessa contemplação silenciosa. Frente a frente, as janelas de Teresa e Simão desenham duas molduras sobrepostas que, reforçadas pelo enquadramento anterior, destacam agora os seus corpos como imagens, aos olhos um do outro e também aos nossos olhos. O efeito desestabilizador depende, aqui, do modo como o espectador é violentamente desviado do regard caméra, e da sugestão de que é à câmara, e portanto a ele, que o monólogo se dirige, para a estranha perceção de que Teresa e Simão estão presentes um ao outro-presentes, mas fisicamente separados; e presentes, mas isolados em quadros separados, que os destacam em imagens especulares e inevitavelmente distanciadas. Duas ilusões de presença são, deste modo, criadas e destruídas no espaço de poucos segundos. Não é recurso único: Amor de perdição poderia, de facto, ser descrito como uma extensa variação deste tropo, como a comentada cena do diálogo entre Teresa e o pai, um pouco mais tarde, claramente sublinha. Aí, o diálogo entre as personagens perturba o espectador pela posição dos seus corpos: Teresa de frente para a câmara, como se falasse para nós, Tadeu desfocado, de lado, falando para um fora de campo não identificável, a voz 
dobrada, inicialmente, pela voz do narrador, e só depois audível. No final da cena, a câmara recua e o logro é revelado. Como recorda Kiraly, os espelhos em Oliveira frequentemente assinalam a natureza de trompe-l'oeil da imagem cinematográfica ("Frames, Windows, and Mirrors" 13), e aqui a imagem de Teresa é, na verdade, o seu reflexo no espelho da parede da sala.

$\mathrm{O}$ duplo monólogo à janela representa ao mesmo tempo o primeiro encontro dos amantes e a forma da sua presença (fílmica) um ao outro: sempre indireta, sempre diferida, sempre desviada para outras personagens ou para o espectador. Mas se estes traços se adequam, por fazer parte do seu funcionamento, à representação da correspondência entre os dois que ocupará a quase totalidade do filme-recorde-se que Teresa e Simão têm apenas um encontro, à noite, no jardim; recorde-se, também, que frequentemente a representação da correspondência no filme oscila entre o monólogo e o diálogo (Lavin 61)-mais significativos se tornam quando convocados para a representação de supostas situações de presença. O mesmo se passa, se quisermos perseguir esta hipótese, quando o filme se concentra na exploração do triângulo amoroso como forma de polarização complexa das representações da presença e da ausência: pense-se na cena em que Simão e Mariana, na Relação, no Porto, partilham o espaço exíguo da cela, fisicamente próximos, enquanto a voz off de Simão lê a carta que escreveu a Teresa, ponto de fuga sonoro que inevitavelmente destina a imagem para um fora de campo que terá o seu correspondente nas grades do quarto de Teresa em Monchique. A destinação epistolar, concentrada na banda de som, desfaz qualquer proximidade entre os dois corpos que a imagem mostra, desmaterializando a presença e subjugando, como ao longo de toda a narrativa, a figura do par amoroso às polaridades irresolúveis do triângulo. Gostaria de sugerir que um dos sentidos que podemos dar à expressão "cinema epistolar" é precisamente este: a sistemática desestabilização das noções de corpo, presença e destinação, naquele "estado de espelho da imagem de cinema" que Fernando Guerreiro identifica em Oliveira (341), e que faz com que estas cenas funcionem, repetidamente, como cartas roubadas - cenas com um ponto de fuga sempre exterior ao plano, destinadas a um fora de campo que, em última instância, converte o espectador num recetor desviado, ou involuntário, de uma destinação esvaziada e insistente. 
Percebe-se assim que não é apenas pela suposta "transposição integral do texto" (Lupi Bello 343) que todas as cartas do texto de Camilo são exploradas no filme, numa variação notável das soluções possíveis para a representação de cenas de escrita e leitura. Teresa e Simão vêem-se, como já apontei, pela primeira vez, emoldurados pelas janelas das respetivas casas, e terão apenas, ao logo de todo o filme, um encontro noturno, os dois corpos imersos na sombra. A partir daí, as cartas que circulam entre os dois amantes são cuidadosamente encenadas, na escrita e na leitura, a partir da separação dos espaços (espaços confinados e grades são os cenários da separação) e a partir de estratégias de mise-en-scène que poderiam ser descritas como variações do tropo da destinatária ausente: através do texto filmado e dobrado por uma voz sem ancoragem física nos planos que constituem a cena, através do texto da carta recitado como monólogo dirigido à câmara ou através da inscrição de um espaço de ausência - sombra ou mesmo recorte-no enquadramento ou constituição do plano, é sempre da inscrição de uma ausência no espaço da comunicação epistolar - e na representação espacial do filme — que se parece falar. Deste modo, o ponto de fuga de cada cena aparece sempre fora de campo, diferido numa remissão para o exterior, num jogo de rimas simétricas que a estrutura do filme torna assimétricas e nunca plenamente complementares, porque sujeitas a uma fragmentação interna. ${ }^{3} \mathrm{~A}$ escrita é assim figura do plano constitutivamente esvaziado deste cinema, pois a presença na ausência que a carta representaria funciona, aqui, em sentido inverso: inscrevendo uma ausência no interior de uma suposta copresença ou correspondência, perturbando a destinação através da interpelação de outros olhares, internos, como os de Mariana e João da Cruz, ou externos, como o nosso. Como sugeria Rosenbaum, a narrativa do filme poderia ser vista como "an explication of what is keeping the couple apart in separate shots, as well as a formal explanation of

\footnotetext{
${ }^{3}$ Segundo Kiraly, "a personagem colocada num lado do plano, ficando a outra metade vazia ou obscura (como a querer assinalar a ausência do destinatário), torna estas cenas espelho ou 'par' das imagens de Teresa escrevendo/lendo cartas. Esta simetria visual, que ecoa a cena em que os dois amantes se vêem pela primeira vez (em janelas uma frente à outra, como em espelhos), confirma a observação de Hamid Naficy sobre o jogo de ausências e presenças subjacente a estas cenas de narrativas fílmicas epistolares: 'o próprio facto de se dirigir a alguém numa carta . . . transforma o destinatário duma figura ausente numa presença, que paira nos interstícios do texto"” ("Cartas no ecrã" 103).
} 
what is binding these shots together" (215). A regra formal e temática do filme é a disjunção; o seu eixo é a carta.

Com a última carta de Teresa a Simão, porém, o jogo de forças altera-se de forma radical: na sequência final de Amor de perdição, o fantasma de Teresa, invadindo a cena enquanto corpo, permite por fim a reunião dos dois amantes num mesmo espaço e num mesmo enquadramento. Nessa diferença fundamental, ganha forma também o discurso sobre a carta que o filme conduz, e que na fantasmagoria que instaura inevitavelmente se confunde-é o meu argumento-com o discurso reflexivo sobre o próprio cinema. Para percebermos este movimento, será importante regressar por momentos ao texto de Camilo.

\section{Última carta}

O último capítulo de Amor de perdição intitula-se "Conclusão": capítulo dentro e fora da sequência dos vinte capítulos, fecha e complementa o arco da ação ao mesmo tempo em que remete para aquela introdução que abria o romance com a citação de um documento, o livro das partidas para a Índia, consultado por Camilo nos cárceres da Relação do Porto. Na "Conclusão," é também, como na introdução, da representação de um texto e das condições da sua leitura que se trata: a última carta da correspondência entre Teresa e Simão, resgatada das águas nas últimas palavras do texto. A carta de despedida de Teresa ocupa toda a parte final e constitui a última grande encenação de um texto estruturalmente definido pela dimensão epistolar que ativa desde o seu início. Mas se, ao longo do romance, as cartas parecem estar sujeitas a serem lidas e relidas, intercetadas, perdidas ou entregues cedo ou tarde demais, alguma coisa de inédito acontece neste momento final.

Recordemos a cena: Simão, subindo ao barco que o levará ao degredo, vê Teresa no mirante a despedir-se dele. No mesmo instante, a mendiga que serviu de intermediária alcança o barco e entrega-lhe um maço de cartas, com uma carta por abrir. Olhando de novo Teresa, Simão vê-a desaparecer, e nesse momento o barco para, tendo a sua viagem suspensa por algumas horas. Ao entardecer, Simão recebe a notícia da morte de Teresa (aparentemente contrariando uma obsessão recorrente: "Ninguém me levará ao degredo a notícia da sua morte! E, quando eu a chamar para que me veja morrer digno 
dela, quem te dirá que eu morri, mártir?!" (212); "Quem te diria que eu morri, se não fosse eu mesma, Simão?” (220)) e sabe - apenas então-que ela morreu enquanto ele a via. À meia-noite Simão, já em viagem para o alto mar, abre, por fim, a carta de Teresa, que começa com estas palavras: "É já o meu espírito que te fala, Simão. A tua amiga morreu. A tua pobre Teresa, à hora em que leres esta carta, se me Deus não engana, está em descanso" (220). É um dos momentos mais impressionantes do livro de Camilo. O diferimento temporal que até então tinha marcado toda a estrutura das relações entre cartas e ações assume agora uma dimensão inédita. Pela primeira vez, as cartas não estão sujeitas a serem lidas e relidas, a serem entregues cedo ou tarde demais, a serem perdidas no caminho: esta carta prevê exatamente o tempo da sua leitura, determina-o, como se a espera de Simão para a ler fosse determinada pela própria natureza do que nela vai escrito.

É evidente, nesse ponto, o contraste com a carta de Simão que, no capítulo $\mathrm{X}$, exatamente a meio do romance, terminava com a frase que marca a abertura desta última carta de Teresa: “À hora em que leres esta carta. . ." (147). Nessa carta imediatamente anterior ao assassinato de Baltasar Coutinho, que aliás nunca será enviada, a frase estava incompleta, tal como ficou incompleta a ação projetada por Simão (morrer matando). O que pertencia ainda ao "conflito de contrários projetos" (139) que caracterizava o Simão adolescente e impulsivo até essa carta central aparece agora superado, recativado, cumprido no termo de uma lenta formação na dor e na culpa que, ao longo da segunda metade do romance, a experiência do encarceramento representa. A carta de morte de Teresa é a verdadeira conclusão do percurso de Simão. A última carta de Teresa prevê uma leitura póstuma, antecipa com precisão o seu efeito-a conversão de Simão num ser para a morte - e corrige retractivamente a trajetória de Simão permitindo que este possa morrer, enfim, amando.

\section{Fantasmas}

Ao longo do Amor de perdição de Oliveira, a representação da carta parece explorar, como vimos, todas as configurações possíveis da polaridade que afeta a comunicação epistolar: a que a faz oscilar, como elemento que supre e se funda sobre a ausência, entre o seu funcionamento como ponte ou como barreira, encontro ou separação, ligação ou distância, como propunha Janet 
Altman no seu estudo sobre a forma epistolar (Altman). No entanto, na cena da última carta estas possibilidades parecem conjugar-se, sobrepor-se, identificarse, num encontro impossível entre remetente e destinatário, escrita e leitura, que parece fazer desta carta, nos termos da conhecida polémica, uma carta que paradoxalmente chega ao seu destino. A carta de morte de Teresa poderia ser descrita com aquele famoso intertítulo do Nosferatu que, na tradução francesa, deixava os surrealistas num misto de alegria e terror: "Quando passou a ponte, os fantasmas vieram ao seu encontro." O encontro final do casal desencontrado só pode ser possível—-tendo a morte inscrita como eixo—num tempo além do tempo.

$\mathrm{Na}$ sequência final, a correspondência entre Teresa e Simão assume o estatuto de fantasmagoria: no tempo póstumo da leitura, o fantasma de Teresa invade a cena, permitindo por fim a reunião dos dois amantes num mesmo espaço. As implicações para a reflexão do filme sobre a natureza da imagem são determinantes, quando a lógica de uma ausência inscrita no coração da imagem se revela. Nos minutos finais, são recuperados alguns dos modos fundamentais de encenação, ao longo do filme, das articulações visuais entre Teresa e Simão. Em todas elas, porém, é de explicitação e releitura que se trata.

No início da sequência final, quando o navio de Simão está prestes a partir, o bote da mendiga aproxima-se para entregar o maço de cartas enviado por Teresa. O rolo de papéis é recolhido por um marinheiro debruçado sobre as águas, que, de baixo para cima, o passa para as mãos de Simão na amurada, antecipando o movimento final do filme, concentrado no emergir dos papéis. A perspetiva é vertical, e ditada pela morte iminente de Teresa. Simão recebe os papéis, ergue o olhar ao mirante, o navio move-se e tem início a cena que mais de perto repete o primeiro encontro dos dois amantes, já aqui descrito. Se, aí, o distanciamento extremo era sugerido pelos monólogos em espelho e pelo espectador como ponto de fuga (o regard caméra só tardiamente revelado contemplação especular dos amantes), agora, numa geometria muito mais oblíqua, a simetria anunciada pelo campo/contracampo é surpreendente: Simão olha, em contrapicado, para o alto, recuando no convés para contrariar o movimento do barco (e da câmara) e manter "os olhos fixos no mirante"; Teresa responde-lhe agitando o seu lenço branco. O ponto fora do plano para onde se dirige o olhar fixo é agora claramente articulado pela inversão do picado/contrapicado, e pela brancura dos lenços que Teresa e Simão agitam, os 
dois espaços, pela primeira vez, parecendo subitamente próximos. Num instante, Teresa desmaia, no meio da comoção das freiras, e o movimento da câmara, que já pudemos identificar com o barco, também para. $\mathrm{O}$ narrador intervém para esclarecer que a viagem tinha sido suspensa devido ao mau tempo, mas a sugestão de um vínculo entre o movimento da câmara e o movimento dos amantes já foi dada. Entre este momento e o paralítico final, Amor de perdição trabalhará insistentemente a ideia de arrêt sur image, que Daney associava, na expressão francesa, às conotações de "detenção" ou "sentença de morte" (242): paragem, ou travagem, que obriga também a uma explicitação reflexiva do seu dispositivo.

Suspenso, no palco do pequeno navio, o filme entrega-se, demoradamente, à releitura epilogal dos seus movimentos. É só então que, pela primeira vez, Amor de perdição reúne, no mesmo plano, os seus três protagonistas. À meia noite em ponto, como diz o narrador, Simão estica "o braço trémulo" e lê por muito tempo a última carta de Teresa. Com Mariana sentada ao fundo, Simão aparece sentado à mesa onde, antes, conversara com o comandante. Se essa conversa era iluminada pela luz amarelada de uma lanterna que o comandante, ao sair, leva consigo, algo de diferente acontece agora, enquanto o narrador fala do "baço clarão da lâmpada." Uma luz branca, forte, ilumina as cartas em cima da mesa. O rapaz ergue o olhar das cartas e da escuridão do camarote-como se entrasse por uma porta, sem que se veja outra porta além da porta aberta para o convés - surge Teresa, avançando, declamando a sua carta, até se sentar à mesa de Simão. De branco, iluminada, parece partilhar a brancura da luz. Avança, e fala, enquanto no plano vemos, ao mesmo tempo, a silhueta de Mariana na sombra e sobre a mesa o braço que focaliza o olhar de Teresa no seu contracampo-Simão.

Não há aqui sugestão de diferimento: é a Simão que Teresa fala, invadindo a cena enquanto efeito de leitura (Simão ergue os olhos da carta, e vê), e enquanto fantasma. Invade-a, porém, (e é o ponto interessante) sem que o filme desloque ou altere o seu regime de representação: sem recorrer a nenhum efeito de alterização da imagem de Teresa para além da luz branca que, como veremos, pautava já outros momentos do filme. O contraste é evidente, mais uma vez com a adaptação de António Lopes Ribeiro, que recorre à sobreimpressão para recriar o fantasma de Teresa na cena. Aqui, é o corpo vivo de Teresa que entra pela porta, mas projetado pelo texto iluminado, fazendo 
implodir uma economia da imagem supostamente realista no gesto duplo de manutenção dos códigos de representação a que o filme nos habituou e de inscrição visível de uma figuração ao mesmo tempo sobrenatural e metacinemática: a carta branca que projeta, no camarote subitamente convertido em lanterna mágica, Teresa como figura de luz.

No entanto, a fantasmagoria dá-se segundo os mesmos recursos que inscreviam, ao longo do filme, a ausência implicada na figura da carta: se a iluminação de Teresa corresponde à carta inicialmente iluminada em cima da mesa, o contraponto com a sombra que cobre o corpo de Simão-sempre presente, mas sempre invisível - é aqui fundamental: reunidos no mesmo plano, Simão e Teresa estão ainda separados, a disjunção operando-se agora por efeito da carta que anima Teresa como presença luminosa. Cinema epistolar, ainda: aquele que faz da carta um modelo para a desestruturação da copresença.

O efeito é acentuado, como se viu, pela presença de Mariana na cena, recolhida a desviada do jogo de iluminação que envolve os amantes, remetendo não tanto para a subjetividade do olhar e do plano (o ponto de vista de Simão, não partilhado por Mariana), quanto para a vinculação entre visão e leitura: a sugestão parece ser a de que só Simão vê Teresa, porque esta é lida na imagem através da carta que a ilumina e cinematograficamente projeta. Ao mesmo tempo, a presença de Mariana ativa o efeito de releitura de que falava: reunidos os três protagonistas no mesmo plano, o filme mantém-nos em planos diferentes. O jogo entre luz e sombra é, também, a encenação de distâncias inscritas. Mariana, ao fundo, não vê nem é vista; Simão vê Teresa, e apenas Teresa, ao longo de toda a carta. Assim que a figura se desvanece, perguntará surpreso: "Estava aqui, Mariana?"

No final da cena, porém, Teresa vê Simão, e aí que Amor de perdição parece subscrever inteiramente a paradoxal duplicidade de uma carta impossível que chega ao destino (ou de uma carta póstuma que, paradoxalmente, tem resposta), invertendo estas relações. No momento em a carta termina com a despedida de Teresa, aquele que era o ponto de vista de Simão transforma-se, subitamente, no ponto de vista do fantasma. Às palavras de Teresa (“Adeus, à luz da eternidade parece que já te vejo, Simão!”), a câmara dá-nos o contracampo do longo plano de declamação da carta, enquadrando as cartas iluminadas, e Simão que, agora debruçado sobre elas, como perseguindo o fantasma de Teresa, recebe sobre o corpo a mesma luz. Se 
o desencontro no interior do mesmo plano irremediavelmente afirmava a natureza cindida de uma imagem em que a ilusão de presença é apenas impressão do fantasma, retroativamente reconfigurando como fantasmagórica toda a imagem de Amor de perdição, é com esta transferência de luz que Oliveira nos dá, ao mesmo tempo, o ponto de vista do além e a entrega da carta, mais uma vez num elaborado contraponto entre imagem e som. Se a leitura da carta de morte permite a Simão ser visto pelo fantasma e através do fantasma, é no fundo a carta o elemento que escreve - na imagem - a condenação de Simão. Depois desta cena, apenas restará a Simão a confirmação de uma morte já consumada na contaminação desta luz mortal.

\section{Aparições}

A propósito dos últimos filmes de Oliveira, Fernando Guerreiro sugere que em obras como Espelho mágico, Benilde ou a virgem-mãe ou $O$ estranho caso de Angélica "se coloca a questão de figurar o extraordinário: as condições de configurabilidade de uma aparição" (340), no quadro da aporia, apontada por Oliveira, de que nem as almas nem os abismos se podem filmar, mas apenas as "coisas concretas" (340). ${ }^{4}$ Gostaria de sugerir que o problema que a última carta de Amor de perdição coloca é da mesma ordem: a representação concreta de um encontro espectral. "Ver-nos-emos no outro mundo, Simão?" perguntava Teresa a Simão numa das últimas cartas. Que a sequência final pareça responder afirmativamente a esta pergunta sem abandonar o regime realista da representação sugere uma deslocação sem retorno do "mundo" das imagens.

Num ensaio de sobre aquela que na altura era ainda a trilogia dos Amores Frustrados, Jacques Parsi comenta o modo como, do ponto de vista temático, os três filmes (Benilde, Amor de perdição e Francisca) acentuam uma aspiração para o alto que determina, necessariamente, o abandono do corpo. Toda a sequência final de Amor de perdição, com a acentuação, como vimos, da verticalidade dos movimentos (da despedida ao mirante à subida das cartas na conclusão, passando pelas escadas para o convés como ponto de fuga da cena

\footnotetext{
${ }^{4}$ Guerreiro recorda duas citações da entrevista com Oliveira do catálogo da Cinemateca de 1981: "Filmar as almas seria o ideal, mas isso não é possível" (340); e "os abismos não se podem filmar, sugerem-se" (340).
} 
fantasmagórica da última carta), parece inscrever-se nessa tensão, e no "flirt com o além" de que fala Parsi (77).

$\mathrm{Na}$ entrevista com que abri este texto, perante a sugestão de Bénard da Costa de que a voz de Oliveira, nesse plano final, nos "devolveria" ao cinema, Oliveira descreve deste modo as forças em causa nesta cena:

M.O. Exato. Reconduz-nos ao cinema. A música, aqueles efeitos, o genérico. Toda essa coisa do cinema. O cinema é a combinação do espaço visível com o espaço invisível. Eu não podia seguir o Simão e a Mariana para o fundo do mar, para a morte. Tenho de ficar no que se vê. Não posso ficar com os corpos. Posso ficar com as cartas.

J.B.C. A mão do marinheiro?

M.O. A mão do marinheiro. Eles vão para o fundo, as cartas vêm para a superfície. São o que fica na imagem. É pelas cartas que conhecemos aquela história toda, não é? (Bénard da Costa 110)

O movimento é duplo. Recorde-se, aliás, que também o era em $O$ velho do Restelo, um dos primeiros exemplos que convoquei. Nesse filme tardio, à imagem inicial do livro que sobe até à superfície das águas, motivada pela sugestão de que "o mar pariu Os Lusíadas," responde um breve plano do mar, após o suicídio de Camilo, que mostra novamente o livro a subir, para ser tragado por uma onda do mar. A aproximação que João Ribeirete fazia entre a superfície transformadora do mar afetando a materialidade do livro e a transposição para celuloide que a adaptação poria em prática, engolindo um texto que se afundaria nas ondas é assim mais importante se tivermos em conta o modo como a verticalidade do movimento deste texto-livro ou cartasparece estar na base da conceção desta encenação. Num certo sentido, é por efeito do afundar dos corpos - peso, contrapeso - que a correspondência, ou o livro, aflora, revelando-se no campo da imagem. Memória, revelação fotográfica, aparição: póstuma, esta condição da imagem como impressão ("é o que fica na imagem") vincula a visibilidade à morte.

No final do texto de Parsi, sugere-se que, no argumento na altura nunca realizado de Angélica, todos os grandes temas da trilogia estariam já contidos: as grades, as vozes, as imagens, a leveza, o anjo. "O filme não foi realizado. No seu lugar há três, vinte anos mais tarde” (Parsi 78). Quarenta anos depois, O 
estranho caso de Angélica permite perceber, entre outras coisas, o papel da luz nestas representações. Pense-se apenas no modo como o filme abre e fecha com referências à luz, da cena noturna inicial à porta da loja Photogenia com as luzes, a custo, a acenderem-se, ao plano final das portadas da varanda por onde Isaac e Angélica, em espírito, terão escapado, a serem fechadas a partir do interior, deixando o filme na escuridão. ${ }^{5}$ Mas pense-se também na dupla associação, conduzida de forma consistente ao longo do filme, entre Angélica e uma luz forte (excessivamente forte- a preparação da primeira animação passa justamente pela troca da lâmpada por uma mais forte), e entre as fotografias e uma iluminação não explicável em termos naturais (pense-se nas imagens do quarto à noite, em que as fotografias no estendal, de tão iluminadas, sem que haja porém sobre elas alguma fonte de luz, parecem iluminar). No início do filme, Isaac lê, alto, um poema de Régio ("Sarça ardente") que ditará a regra disjuntiva desta figuração espectral: "Anjos! abri-me o pórtico dos céus / Que em minha noite é dia."

Na cena final do Amor de perdição, a luz das cartas que se projeta sobre Simão é claramente associada à "luz da eternidade" de que fala Teresa. Recuando um pouco no filme, recordaremos o contraste entre a noite sem luz do encontro dos amantes e a luminosidade do seu encontro epistolar, e reconheceremos o mesmo jogo de luzes na carta que, como assinalei neste texto, faz par com a carta final do romance: a carta que Simão escreve antes de matar Baltasar Coutinho, descrevendo a sua intenção de morrer matando. Oliveira dedica vários minutos a essa cena, enquadrando Simão, de pé, a declamar a carta, num estreito retângulo que o posicionamento da câmara noutro quarto, além da porta, determina. O efeito é o de recortar uma faixa de luz num plano maioritariamente negro. Nessa faixa, Simão aparece iluminado por uma luz branca, aparentemente com origem na janela aberta que está por trás dele, enquanto começa por dizer: "Considero-te perdida, Teresa. O sol de amanhã pode ser que eu o não veja. Tudo, em volta de mim, tem uma cor de morte. Parece que o frio da sepultura me está passando o sangue, e os ossos." Minutos mais tarde, a cena interrompe-se, como a carta, com as palavras de morte: "à hora a que leres esta carta"; com a interrupção, o plano escurece subitamente, e a câmara aproxima-se da porta, eliminando o recorte negro-

\footnotetext{
${ }^{5}$ Guerreiro sublinhará a etimologia do termo photogenia, aludindo à produção de luz (380).
} 
sepulcral—que emoldurava Simão. Este, agora sentado, debruça-se sobre a mesa, em desespero, e fica inerte, enquanto Mariana, que entra no quarto, fecha a janela e acende uma a uma as velas que devolvem luz ao quarto. É já outra luz, agora, ou uma luz de outra cor. Como no encontro noturno entre Teresa e Simão, perdeu-se a perturbadora visibilidade desta iluminação excessiva. À luz fria da morte regressaremos apenas com a carta de Teresa, que cumpre e completa esta carta de Simão: "É já o meu espírito que te fala."

Se muito se disse sobre a "fidelidade" de Oliveira ao texto de Camilo, e sobre a integralidade da sua adaptação, pouca atenção se deu ao modo como o argumento do filme cuidadosamente edita e reescreve a prosa de Amor de perdição. Desse trabalho, como já sugeri, o excerto do prefácio que aparece inscrito no ecrã, no fim do filme, parece ser uma figura. Mais importante, talvez, é o tratamento dado à última carta de Teresa, tão determinante na economia do filme: do texto da carta do romance, foram cuidadosamente removidas todas as referências ao tempo e ao espaço da cena de escrita (esse tempo e espaço duplos, em que as cartas nos falam ao mesmo tempo do envio e da receção): onde Teresa dizia: "à hora em que leres esta carta," "à hora que te escrevo," "nas tuas cartas, que li há pouco," "perderás de vista este mirante," "entrarás na nau dos degredados," "vou ver a minha última aurora" (Castelo Branco 220-22), encontramos agora apenas um tempo presente, único, e o espaço presente, no qual o espírito de Teresa fala a Simão: "vi a minha última aurora," "entraste na nau dos degredados." Não há outro momento do filme em que Oliveira se afaste tão dramaticamente do texto e do funcionamento da carta-acontece sempre, como vimos, o contrário: uma submissão obsessiva aos seus mecanismos - e se isso aqui acontece, é apenas porque a submissão é mais radical: fantasmagoria plena, a imagem é aqui fantasma de uma escrita que ao mesmo tempo absorveu e despediu. Neste cinema, poderíamos dizer, só há presente, porque todo o presente é já ausente. Percebe-se então que quando ouvimos Teresa dizer, no lugar de "eu devia poupar-te a esta última tortura; não devia escrever-te" (Castelo Branco 220), a frase "eu devia poupar-te a esta última tortura; não devia aparecer-te," não estamos apenas perante uma marca da adaptação (o texto convertido em imagem), nem mesmo perante a sugestiva indicação uma equivalência entre escrever e projetar, ler e ver. O fantasma que aparece para se descrever como aparição, elidindo com o corpo a própria carta, é provavelmente a mais radical subscrição a um regime epistolar no filme de 
Oliveira, definição precisa do estatuto fantasmagórico da imagem cinematográfica. Como dizia Kafka numa famosa carta a Milena, é um "comércio de fantasmas" (302).

\section{Obras citadas}

Altman, Janet. Epistolarity: Approaches to a Form. Ohio State UP, 1982.

Bénard da Costa, João. "Uma entrevista com Manoel de Oliveira." Manoel de Oliveira: cem anos, Cinemateca Portuguesa, 2008, pp. 25-116.

Camões, Luís Vaz de. Os Lusíadas. Porto Editora, 2015.

Castelo Branco, Camilo. Amor de perdição, memórias duma família. Ulisseia, 1981.

- Memórias do cárcere. Viúva Morè, 1862.

Daney, Serge. O cinema que faz escrever: Textos críticos. Angelus Novus, 2015.

Guerreiro, Fernando. Cinema El Dorado: cinema e modernidade. Colibri, 2015.

Kafka, Franz. Briefe an Milena. S. Ficher Verlag. 1983.

Kiraly, Hajnal. "Cartas no ecrã: a representação da correspondência escrita em adaptações de Amor de perdição." A escrita do cinema: ensaios, editado por Clara Rowland e José Bértolo, Documenta, 2015, pp. 172-89.

-. "Frames, Windows, and Mirrors. Sensing Still Bodies in films by Manoel de Oliveira." Acta Universitatis Sapientiae, vol. 8, no. 1, 2014, pp. 7-20.

Lavin, Mathias. La parole et le lieu: le cinéma de Manoel de Oliveira. PU de Rennes, 2008.

Lupi Bello, Maria do Rosário. Narrativa literária e narrativa fílmica: o caso de Amor de perdição. Fundação Calouste Gulbenkian, 2005.

Melville, Herman. "Bartleby." Billy Budd, Sailor and Other Stories, editado por Frederick Busch, Penguin, 1986, pp. 1-46.

Murnau, Friedrich Wilhelm, realizador. Nosferatu, eine Symphonie des Grauens. Prana Film, 1922.

Oliveira, Manoel de, realizador. Amor de perdição. Centro Português de Cinema, 1979.

—. Benilde, ou a virgem mãe. Centro Português de Cinema, 1981.

—. Espelho mágico. Filbox Produções, 2005.

—. Francisca. V.O. Filmes, 1981. 
—. "Non” ou a vã glória de mandar. Madragoa Filmes, 1990.

—. O estranho caso de Angélica. Les Films de l’Après-Midi, 2010.

—. O velho do Restelo. Epicentre Films, 1981.

Parsi, Jacques. "A trilogia dos amores frustrados." Manoel de Oliveira, Cinemateca Portuguesa, 1981, pp. 71-78.

-, e Antoine de Baecque. Conversas com Manoel de Oliveira. Campo das Letras, 1999.

Preto, António. Manoel de Oliveira: o cinema inventado à letra. Público/Fundação Serralves, 2008.

Ribeirete, João. "Escrever devagar a morte em 'Non' ou a Vã Glória de Mandar." Falso Movimento: estudos sobre escrita e cinema, editado por Clara Rowland e Tom Conley, Cotovia, 2016, pp. 80-92.

Rosenbaum, Jonathan. "Doomed Love: The Masterpiece You Missed.” Placing Movies: The Practice of Film Criticism, U of California P, 1995, pp. 21317.

Truffaut, François, realizador. La chambre verte. Les Films du Carrosse, 1978.

—. Les deux anglaises et le continent. Les Films du Carrosse, 1971. 